\title{
Correction to: The seaweed Prasiola crispa (Chlorophyta) neutralizes toxic effects of Bothrops jararacussu snake venom
}

\author{
Ana Cláudia Rodrigues da Silva ${ }^{1}$. Alberto Max Gonçalves Pires ${ }^{1}$. Carlos José Brito Ramos ${ }^{2}$ - Eládio Flores Sanchez ${ }^{3}$. \\ Diana Negrão Cavalcanti ${ }^{2}$ • Valeria Laneuville Teixeira ${ }^{2}$. André Lopes Fuly ${ }^{1,4}$
}

Published online: 14 July 2021

(c) Springer Nature B.V. 2021

\section{Correction to: J Appl Phycol}

https://doi.org/10.1007/s10811-016-0895-3

The authors regret to inform that there is an error in the protocol number of the authorization of the Committee for Ethics in Animal Experimentation. The revised number is Publisher's note Springer Nature remains neutral with regard to jurisdictional claims in published maps and institutional affiliations. presented below, as follow:

Experiments performed were approved by the UFF Institutional Committee for Ethics in Animal Experimentation (protocol number 667) and were in accordance with the guidelines of the Brazilian Committee for Animal Experimentation (COBEA).

The authors would like to apologize for any inconvenience.

1 Department of Molecular and Cellular Biology,

Institute of Biology, Federal Fluminense University,

Niteroi 24020-141, RJ, Brazil

2 Department of Marine Biology, Institute of Biology, Federal Fluminense University, Niteroi 24020-141, RJ, Brazil

3 Ezequiel Dias Foundation, Belo Horizonte 30510-010, MG, Brazil

4 Departamento de Biologia Celular e Molecular, Instituto de Biologia, Universidade Federal Fluminense, Outeiro de São João Batista, s/n, $3^{\circ}$ andar, sala 310, ZIP: 24020-141 Niterói, RJ, Brazil 